\title{
Design of a sun tracker for the automatic measurement of spectral irradiance and construction of an irradiance database in the 330-1100 $\mathrm{nm}$ range
}

\author{
J. Cañada ${ }^{\mathrm{a}, *}$, M.P. Utrillas ${ }^{\mathrm{b}}$, J.A. Martinez-Lozano ${ }^{\mathrm{b}}$, R. Pedrós ${ }^{\mathrm{b}}$, \\ J.L. Gómez-Amo ${ }^{\mathrm{b}}, \mathrm{A} \cdot \mathrm{Maj}^{\mathrm{a}}$ \\ ${ }^{a}$ Departamento de Termodinámica Aplicada, Universidad Politécnica de Valencia, Camino de Vera, \\ s/n. 46022 Valencia, Spain \\ ${ }^{\mathrm{b}}$ Departamento de Física de la Tierra y Termodinámica, Facultat de Física, Universitat de Valencia, \\ 46100 Burjassot (Valencia), Spain
}

Received 27 March 2006; accepted 7 November 2006

Available online 4 January 2007

\begin{abstract}
An automatic global and direct solar spectral irradiance system has been designed based on two LICOR spectroradiometers equipped with fibre optics and remote cosine sensors. To measure direct irradiance a sun tracker based on step motors has been developed. The whole system is autonomous and works continuously. From the measurements provided by this system a spectral irradiance database in the 330-1100 $\mathrm{nm}$ range has been created. This database contains normal direct and global horizontal irradiances as well as diffuse irradiance on a horizontal plane, together with total atmospheric optical thickness and aerosol optical depth.
\end{abstract}

(C) 2006 Elsevier Ltd. All rights reserved.

Keywords: Sun tracker; Direct solar spectral irradiance

Abbreviations: AERONET, Aerosol Robotic Network; AOD, Aerosol Optical Depth; FOV, Field of View; FWHM, Full-Width Half-Maximum; PAR, Photosynthetically Active Radiation; PTFE, Polytetrafluoroethylene; SMARTS2, Simple Model of Atmospheric Radiative Transfer of Sunshine; SUSIM, Solar Ultraviolet Spectral Irradiance Monitor; UV, Ultraviolet Radiation; UVA, Ultraviolet A Radiation; UVB, Ultraviolet B Radiation

*Corresponding author. Tel.: + 34963877321 ; fax: + 34963877329.

E-mail address: jcanada@ter.upv.es (J. Cañada). 


\section{Nomenclature}

$E_{0 \lambda} \quad$ incident radiation at the top of the atmosphere $\left(\mathrm{W} / \mathrm{m}^{2} \mathrm{~nm}\right)$

$E_{n \lambda} \quad$ incident radiation at normal incidence $\left(\mathrm{W} / \mathrm{m}^{2} \mathrm{~nm}\right)$

$G \quad$ integrated global irradiance on a horizontal plane $\left(\mathrm{W} / \mathrm{m}^{2}\right)$

$G_{0} \quad$ extraterrestrial global irradiance on a horizontal plane $\left(\mathrm{W} / \mathrm{m}^{2}\right)$

$G_{N} \quad$ integrated direct normal irradiance $\left(\mathrm{W} / \mathrm{m}^{2}\right)$

$G_{0 N} \quad$ integrated extraterrestrial direct normal irradiance $\left(\mathrm{W} / \mathrm{m}^{2}\right)$

$G_{N E} \quad$ integrated direct normal irradiance $\left(\mathrm{W} / \mathrm{m}^{2}\right)$

$G_{\lambda} \quad$ global horizontal spectral irradiance $\left(\mathrm{W} / \mathrm{m}^{2} \mathrm{~nm}\right)$

$G_{B \lambda} \quad$ direct normal spectral irradiance $\left(\mathrm{W} / \mathrm{m}^{2} \mathrm{~nm}\right)$

$G_{D \lambda} \quad$ diffuse horizontal spectral irradiance $\left(\mathrm{W} / \mathrm{m}^{2} \mathrm{~nm}\right)$

$m \quad$ relative optical airmass

Greek letters

$\alpha \quad$ Angstrom wavelength exponent

$\beta \quad$ turbidity coefficient

$\lambda \quad$ wavelenght $(\mathrm{nm})$

$\rho \quad$ mean relative Sun-Earth distance

$\tau_{\mathrm{T} \lambda} \quad$ total atmospheric optical depth

\section{Introduction}

There is currently increasing interest in reliable experimental data on spectral solar radiation at ground level that can give more specific information than (wide band) integrated radiation for which there is already an adequate global network of measuring stations. This interest is justified since these spectral data allow integrated values to be obtained that refer to specific zones of the solar spectrum such as UVA, UVB, PAR etc., and also to deepen knowledge of the composition and processes that take place in the terrestrial atmosphere, by using radiative transfer codes or inversion algorithms.

The establishment of systematic measurements that allow a complete database of multiuse solar spectral irradiance is fundamental not just for the rigorous validation of transmission models and the determination of atmospheric optical characteristics but also for the design and evaluation of the efficiency of numerous solar radiation energy systems such as, for example, those based on photovoltaic conversion. At the same time, it is of interest in applications as diverse as biomass production, luminous efficacy, plastic materials degradation, erythemal efficiency determined by weighting each wavelength of the solar spectrum by its effectiveness in producing erythema (action spectrum) and then integrating over the UV range, photocatalytic detoxification and the calibration of solar radiation sensors, among others.

The systematic study of the spectral distribution of ground-level solar irradiance has been the objective of many projects, notably those carried out by the National Renewable Energy Laboratory (NREL) [1-3]. During the last few years, spectral irradiance measurement systems have proliferated. On the one hand, there are the systems dedicated 
to the UV range due to public concern caused by the thinning of the stratospheric ozone layer and the consequent increase in UV radiation interacting with the biosphere [4,5]. On the other hand there are specific developments for studying atmospheric aerosols, analysing the optical and radiative properties of aerosols over the length of an atmospheric column from the experimental records provided by radiometers that combine solar spectral irradiance extinction measurements (direct radiation) and sky radiance (diffuse radiation). In this context, the AERONET network [6] has turned into a very useful instrument for analysing the spatial distribution at a planetary level, and for beginning to establish an aerosol climatology $[7,8]$.

Besides these measurement networks, a great amount of field campaigns have been undertaken to determine the optical properties of the atmospheric components using spectroradiometers provided with collimators, usually manually operated. In these campaigns the spectroradiometer Licor 1800 has been widely used [9-13] and its validity has been proved beyond doubt [14-16].

Any experimental measurement programme should be capable of satisfying, at least potentially, a variety of interests. Apart from the interest in the measurements themselves, we must consider what secondary products we wish to obtain from them and, based on these objectives, design the experimental set up and the database accordingly. In our case there is a double objective: to obtain a database of representative spectral solar irradiance for a wide range of optical masses and atmospheric conditions, and to apply the database to the characterisation of atmospheric aerosols, concentrating specifically on the aerosol optical depth (AOD) and the aerosol size distribution.

Since the AOD is determined from the spectral irradiance measurements at normal incidence using the Bouger-Lamber-Beer exponential law [11], to address the second objective measurements of spectral global irradiance on a horizontal plane are insufficient as it is necessary to also know values of direct irradiance, or in any case, the spectral diffuse irradiance. Currently, there exist commercial instruments for studying aerosols, which are used in more or less extensive networks, which give measurements of direct irradiance by tracking the sun [6] or measurements of diffuse irradiance by covering the solar disc over the sensor using some automatic system [17]. Both such systems limit their range to specific spectral bands by, for example, using incorporated filters. This also limits their interest as valid instruments for the study of spectral solar irradiance.

To measure direct irradiance, whether spectral or wide band, it is necessary to use a sun tracker. There are a number of commercially available trackers and the literature contains works showing the design and construction of tracking systems for direct irradiance measurements with pyrheliometers or for tracking the sun on two-axis concentration captors [18-21]. In our case we have designed a sun tracker according to our specific needs and for a relatively low cost. It is part of an automatic system for global and direct spectral solar irradiance measurement, based on two LICOR-1800 spectroradiometers equipped with fibre optics and remote cosine sensors.

\section{Irradiance measurement instrumentation}

The spectroradiometers used to spectral measurements (global and direct) are LICOR 1800 models. The LICOR 1800 is a single monochromator spectroradiometer in the $300-1100 \mathrm{~nm}$ range. The optical receiver is a Polytetrafluoroethylene (PTFE, brand name Teflon ${ }^{\circledR}$ ) dome with a $2 \pi$ steradian field of view (FOV). The monochromator is a 
motor-driven scanning type holographic grating with a $6 \mathrm{~nm}$ full-width half-maximum (FWHM) and a band pass precision of $1 \mathrm{~nm}$. The detector is a silicon photodiode operating in the photovoltaic mode. For the measurement of the direct component a radiance limiting tube (collimator) with FOV of $4.6^{\circ}$ was coupled to the remote cosine receptor.

Various authors have estimated the order of magnitude of the errors that affect the measurements from the LICOR 1800, although the most complete analysis in this respect was carried out at the NREL [2,14,22]. In that work they have taken into account the factors that can introduce some type of uncertainty in the experimental values - both the inaccuracies of the measurement apparatus and those due to random causes such as temperature fluctuations or calibration instrument errors. Recently Martínez-Lozano et al. [16] have analysed the uncertainty associated with the measurements of these spectroradiometers in the visible range. The overall uncertainty (root square sum of the uncertainties) is $\pm 5.0 \%$. If only uncertainties associated with the measurement procedure are considered this value is reduced to $\pm 4.0 \%$. These values agree with those estimated by Riordan et al. [2], Myers [22] and Carlund et al. [15].

In our system, and given that the measurements were made continuously, in order to avoid leaving the instruments exposed to the atmospheric conditions a fibre optic probe provided by the manufacturer was coupled to the instrument. The fibre optic is $1.7 \mathrm{~m}$ long and a small remote cosine receiver is fitted to one end. The fibre optic and remote cosine receiver replace the standard cosine receiver (diffuser) of the Licor-1800, and is connected to the spectroradiometer in its place. The length of the fibre optic conditions, the position of the measurement system and the design of the sun tracker for direct irradiance measurements as will be seen below. The use of the fiber optic has the important limitation that invalidates the UVB spectral range $(300-320 \mathrm{~nm})$. Nevertheless, we have to keep in mind that in such range the instrument shows the maximum error, around $20 \%$ [16], which makes it not suitable for the spectral UVB measurement. The radiance limiting tube, used for the direct irradiance measurements, has been designed based on the work of Cannon [23]. The spectroradiometers are calibrated periodically using a calibrated $200 \mathrm{~W}$ quartz tungsten halogen lamp (LICOR-1800-02 Optical Radiation Calibrator) in the laboratory of the Valencia University Solar Radiation Group.

For the continuous measurement of direct irradiance the sun tracker has been designed based on pass motors, which are described in the following section. The tracker and the spectroradiometers are controlled from a PC using the software developed specifically for this measurement system. The whole of the measurement station is represented schematically in Fig. 1.

\section{Characteristics of the sun tracker}

The sun tracker for direct irradiance has been developed in collaboration between members of the Robotics Institute [24] and the Department of Thermodynamics of the University of Valencia. The design was based on the following requirements:

- To follow the Sun's trajectory with a maximum positional error of $2^{\circ}$. To calculate the Sun's position the algorithm proposed by Blanco-Muriel et al. [25] has been used.

- To control the spectroradiometer such that the measurements taken are synchronised with the position of the system. 


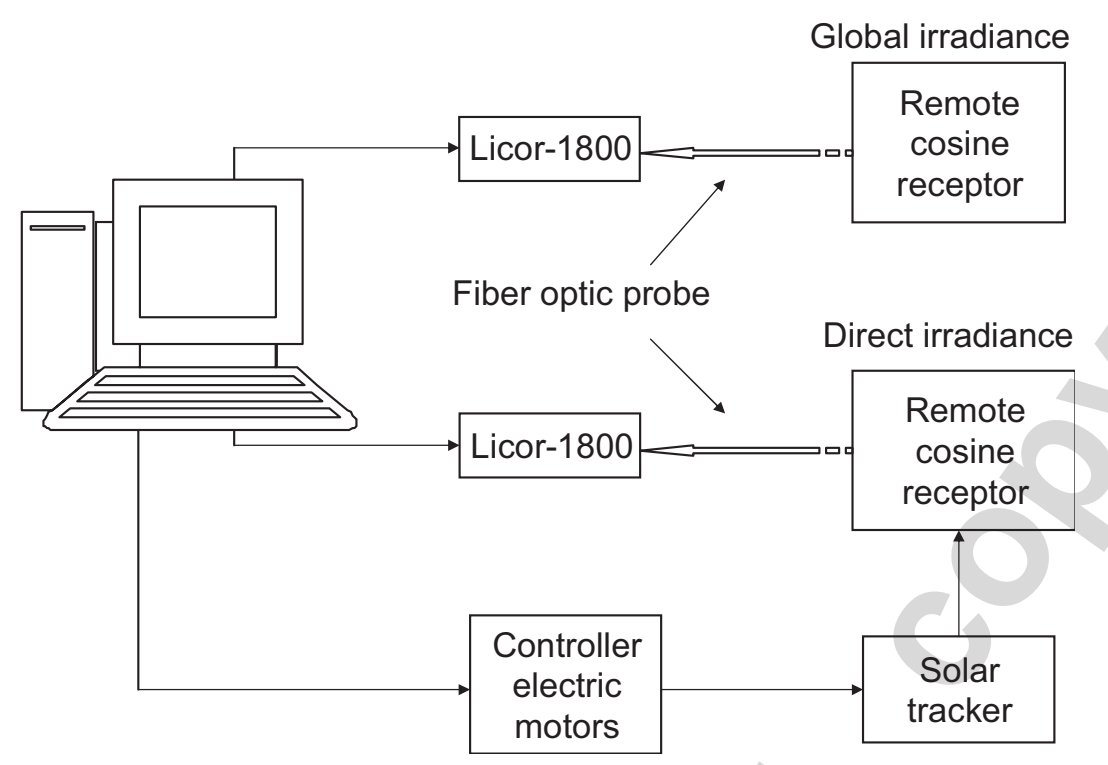

Fig. 1. Scheme of the station for automatically registering direct and global spectral irradiance.

- To work automatically, allowing up to 1 week without the need for any operator supervision.

- To return each night to a rest position avoiding turning back over itself since this would cause the optical fibre to roll up and eventually break.

The development of the tracker required both hardware and software. The hardware designed consists of a mechanical platform that must be outdoors where the collimator and the fibre optic should be placed. The movement of the whole system is commanded by a step motor and gear speed reducer to adjust the step required. Respect to the software, this had to be able to achieve at least the following objectives: (a) to control the tracker to align it with the sun, (b) to implement the equations that model the relative Sun-Earth movement, and (c) to control the spectroradiometer to take the measurements, synchronising the tracker and measurement sensor systems.

\subsection{Hardware}

The system was designed to perform movements in two planes to align the collimator with the sun: one rotation in the azimuth plane over a fixed base, and the other rotation in the principal solar plane, giving two degrees of freedom. The choice of mechanical structure was made bearing in mind that it should support the collimator and the optic fibre. To reduce weight the collimator was made of PVC, without lenses, so that its weight was less than $1 \mathrm{~kg}$. The system chosen is made of a fixed base anchored to a vertical wall formed by two lateral walls and a base on top of these. Above the base, another inverse structure is positioned that turns and supports the collimator. On the base of the lower structure the step motor is set that turns the upper structure (rotation in the azimuth plane), and on one of the lateral walls of the upper structure the second step motor is fixed (rotation in the principal plane).

The join between the two structures is achieved by a step motor-reducer axis and a cylindrical bearing. The attachment of the collimator to the upper structure is by a bracket 
supported to one end of the step motor-reducer axel that controls the solar altitude. The whole of the structure is made on $1 \mathrm{~cm}$ thick aluminium. This material was chosen for several reasons: (a) it is easy to work with, (b) it is weather resistant, and (c) its weight causes no additional problems for the development of the structure. For the actuation systems step motors were chosen rather than continuous current systems for various reasons. Amongst these was the ease of control for positioning and the high blocking torque, which is very useful in this case since most of the time the system is not moving and it is necessary to keep the structure fixed. The disadvantage of the step motors is their maximum resolution, which uses to be too high, that is the reason what step reductions are necessary. Their disadvantage is the maximum resolution of the electrical coils, for which reductions are necessary. From the many ways to achieve this (reducer boxes, toothed bands, worm screws) reducer boxes were selected. In this way a higher motor resolution as well as an increase in their torque is achieved. The motors used were four-phase step motors with a $1.8^{\circ}$ step. They are fed by a $12 \mathrm{~V}, 0.6 \mathrm{~A}$ supply. Their blocking torque is $500 \mathrm{mNm}$ and the breaking torque is $30 \mathrm{mNm}$. The reducer boxes had a 25:1 ratio, allowing $0.072^{\circ} / \mathrm{step}$, sufficient for the desired objective. The pass motor control is done by a control board that was specially designed for this type of motor, including a compatible interface that is connected to the parallel port of the PC through optical couplers.

Finally to give the system a reference point from which to correctly position itself two on/off sensors indicating the initial position for each of the degrees of freedom have been used. These are optical pass detectors made of an LED and a photodetector working in the infrared. To cut the sensors at the desired position fixed aluminium reference point are used that identify geographic north and the zero solar elevation. Fig. 2 shows the sun tracker with the step motor, the limiting tube and the fibre optic all mounted on the metal platform.

In turn, the spectral irradiance measurements on the horizontal plane are performed by a remote cosine receiver connected to the spectroradiometer through an optic fibre probe. Fig. 3 shows the system mounted on a metal platform, which is set horizontal using a bubble type spirit level. In these conditions the error that the use of the fiber optic induces, as it was mentioned above, invalidated the measurements in the UVB range. On the other hand, the authors have also estimated, using the Nakajima's SKYRAD.PACK code $[26,27]$, the contribution of the sky radiance to the measured irradiance, due to the fact that the solid angle subtended by the collimators is higher than the solid angle subtended by the sun. The inaccuracy due to the circumsolar radiation, for $500 \mathrm{~nm}$, was $0.6 \%$ assuming that the sun was perfectly centred in the instruments FOV [16,28]. When the Sun was not in the centre, the circumsolar radiation would probably be slightly less, and so too the inaccuracy due to this radiation. The inaccuracy due to the positioning, with a maximum error of $2^{\circ}$, has not been evaluated.

\subsection{Software}

In the design of the software there are two clearly distinct modules, one for the control of the spectroradiometers and the design of the measurement procedures, and one for the control of the tracker and its movement through the day. The first of these modules has been developed from a layer-based design (Fig. 4). In the lowest level is found the layer responsible for management of the communications between the PC and the spectroradiometer. In the intermediate level is located the layer corresponding to the command and 


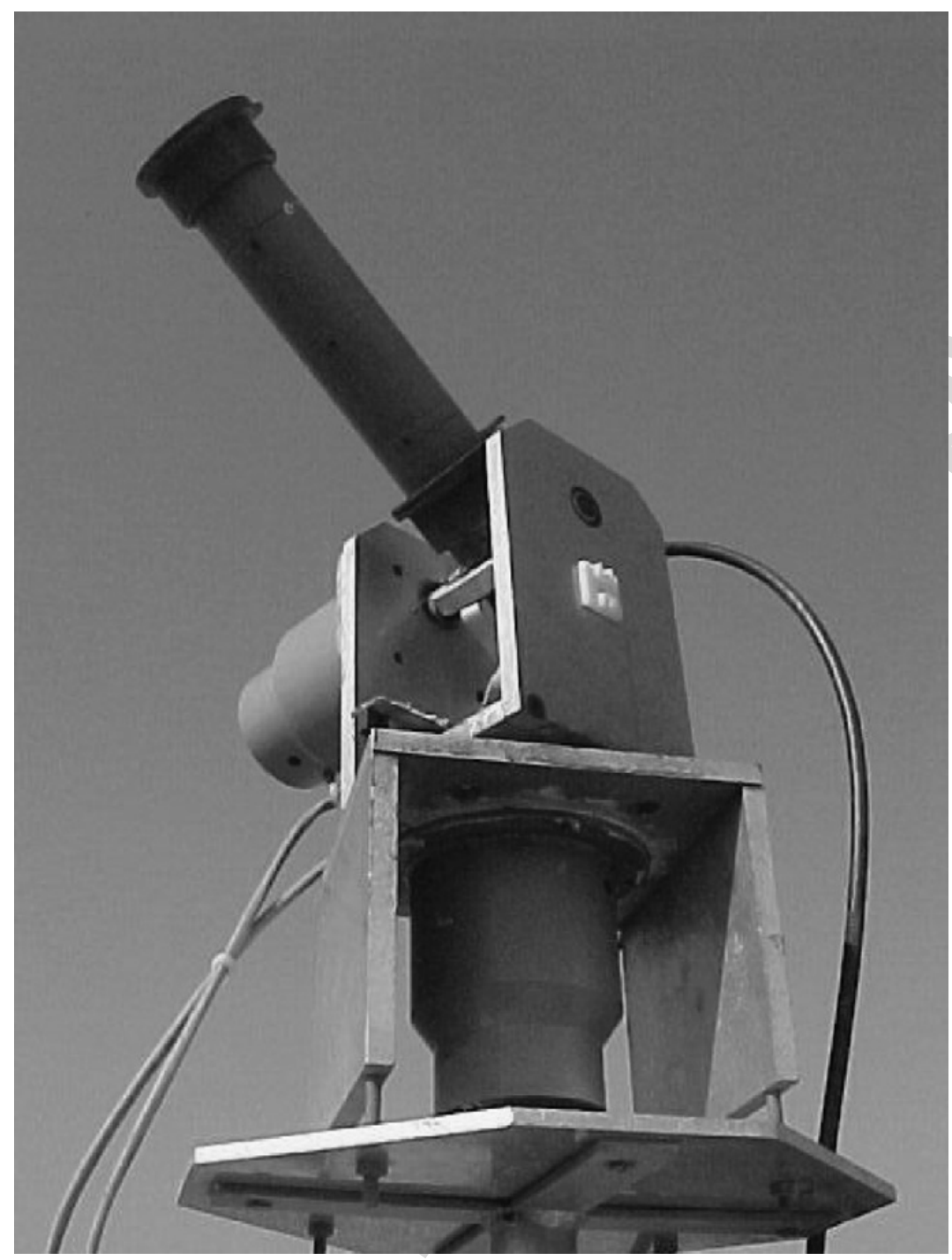

Fig. 2. The sun tracker mounted on the metal platform. The pass motors, radiance limiting tube and fibre optic can be seen.

reply generator through which the user interacts with the Licor internal computer using a menu of simple two character commands to control all phases of instrument operation. In the top layer is located the data processor and storage. The objective of this last layer is to interpret the data returned by the lower layers and display them in a valid way for the user.

The model responsible for the control and positioning of the tracker carries out the functions corresponding to: (a) movement relative to the sun, (b) motor control, (c) adjustment and return to the rest position, and (d) alarms and sensors. The sensors charged with positioning the system are managed using a module that acts as interface between the parallel port and the rest of the program. Using these sensors, various alarms have been defined at different levels that range from simple informative calls to severe alarms in case of misalignment of the system.

All the software has been developed in $\mathrm{C}++$ Builder under a Windows environment, permitting the development of the modular-layered control design in a simple way, practically through a simple translation between the design and the implementation. All the equations needed for the control module of the tracker have been implemented from a 


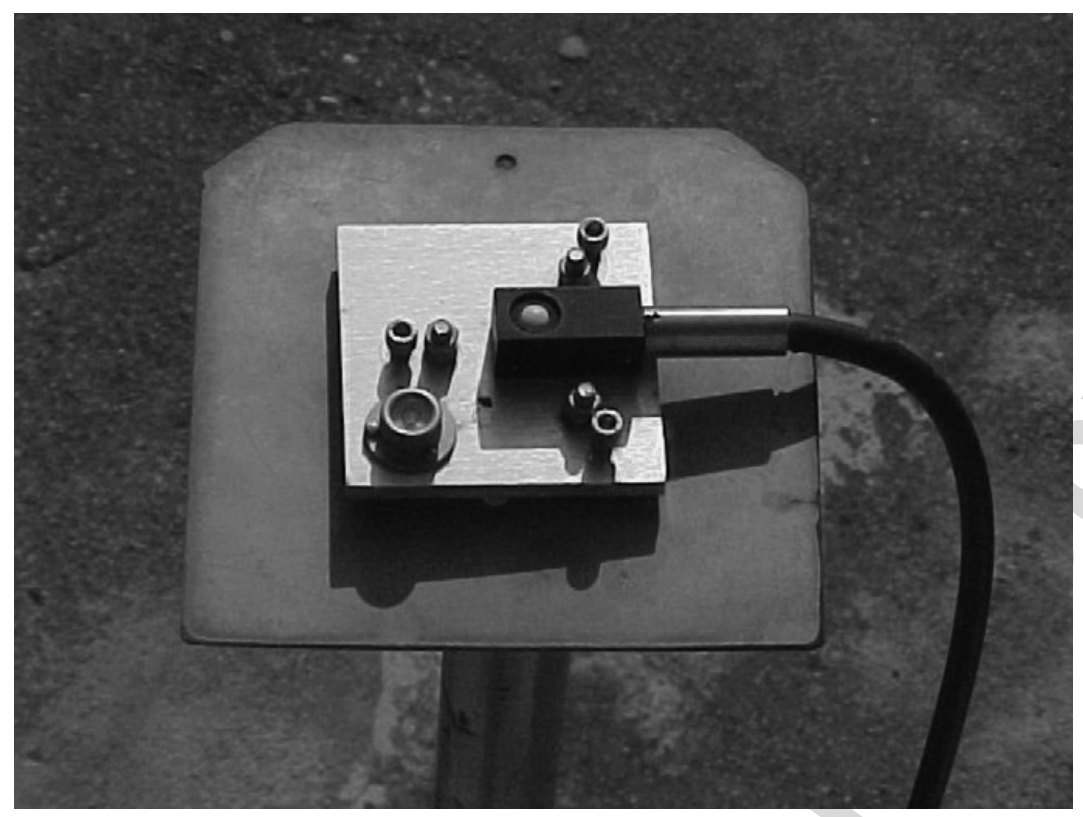

Fig. 3. The remote cosine receiver connected to the spectroradiometer (with the fibre optic probe) mounted on the metal platform.

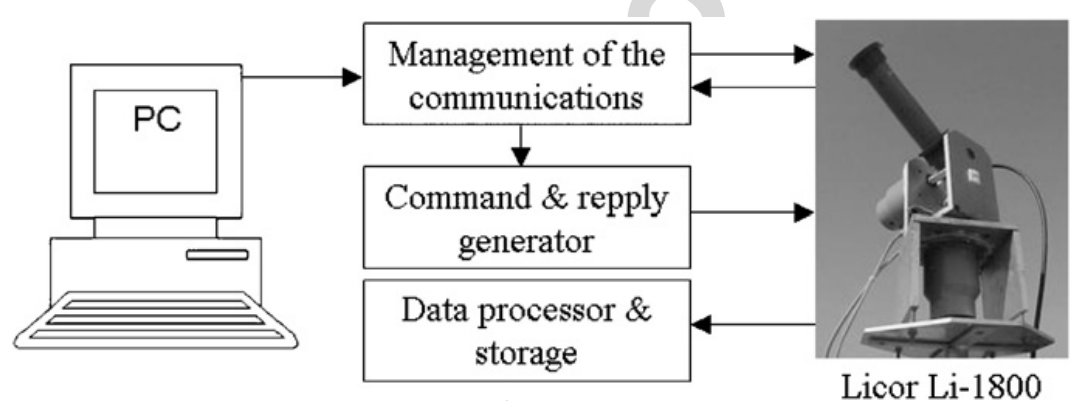

Fig. 4. Software operational diagram.

library. The designed application includes various Menu options whose principal characteristics are as follows:

- File: allows the selection of the functions performed on data files. Files can be transferred from the LICOR to the PC or vice versa, or files in the LICOR memory can be listed and deleted.

- Configuration: contains the communication parameters, geographic coordinates and the measurement instrument's calibration. It is possible to define the type of communication between the LICOR and the PC (indicating the communications port and the data transfer velocity), and to configure the solar tracker by indicating the latitude and longitude of the measurement site and the initial and final solar altitudes at which the system should start operating or return to the rest position, respectively. In this menu, it is also possible to activate the network connection allowing time synchronisation and to send alarms by e-mail.

- View: displays the LICOR parameters (internal date of the LICOR, internal battery power, etc.). 
- Measurement: fixes the measurement parameters. This allows the definition of the scanning interval (process of collecting spectral data). In our system the interval has been set at $15 \mathrm{~min}$. The user specifies the destination file, the upper and lower wavelength limits (330 and $1100 \mathrm{~nm}$ in our case), and the number of scans. It is also possible to activate and deactivate automatic scanning.

- Motors: allows the adjustment of the position in altitude and azimuth, the blocking and deblocking of the motors, and the return to the rest position. This position has been defined as zero solar altitude and $90^{\circ}$ azimuth (taking zero azimuth to the south). In the rest position the collimator is oriented to the north and in a horizontal position. The position adjustment system is very useful since it permits the tracker position to be corrected at any time to ensure the correct orientation of the collimator.

\section{Database}

As has already been stated, a double objective was sought with the system: (a) to automatically obtain direct normal and global horizontal spectral solar irradiance, and (b) based on these to calculate atmospheric aerosol optical properties (such as the AOD, the Angstrom turbidity coefficient and the $\alpha$ power wavelength coefficient). This means that the database structure should take into account both aims.

\subsection{Spectral irradiance}

The measurements, whether direct normal or global horizontal spectral irradiance, are made every $15 \mathrm{~min}$ on universal time convention (UTC). Fig. 5 shows, as an example, the direct normal, global horizontal and diffuse horizontal irradiance values as measured in Valencia $\left(39.48^{\circ} \mathrm{N}, 0.3^{\circ} \mathrm{W}\right)$ at $1200 \mathrm{UTC}$ on 26 May 2003. The diffuse irradiance values have been calculated from the measurements of direct and global irradiance. The inaccuracy in the measurement of the global irradiance in the visible range is $5 \%$, while in the measurement of the direct irradiance is below 3\% [16]. Using these values, a conservative approximation for the inaccuracy in the diffuse irradiance in the visible range would be $8 \%$. It would be possible to apply the shade/unshade method on the global spectra to see if they are consistent with the direct spectra, and thus double check the respective calibrations, but this analysis has not been carried out.

In the UV range, there is a wavelength shift of nearly $1 \mathrm{~nm}$ through the day due to temperature variations [16]. This effect, which has been previously reported by other authors $[5,29]$, is due to the expansions that occur in the holographic diffraction gratings, which are not temperature stabilized, unlike the detector, which is stabilized for the Peltier effect. In the UV range the algorithm of Slaper et al. [30] can be used with a reference spectrum for extraterrestrial solar irradiance obtained from the Solar Ultraviolet Spectral Irradiance Monitor (SUSIM) experiment [31]. The extraterrestrial solar irradiance spectrum is a stable reference that can be used for analysing a posteriori any wavelength shift.

In the database, a file is generated daily for the direct irradiance and the irradiance on a horizontal plane. In this file the first column is the wavelength, varying between 330 and $1100 \mathrm{~nm}$ in $1 \mathrm{~nm}$ steps. The measurements start at $330 \mathrm{~nm}$ and not $300 \mathrm{~nm}$ because the use of the fibre optic greatly increases the errors in this wavelength range. The following columns of the file are the irradiance values for each measurement (UTC time values that appear in the header of each of the columns). Measurements are made each $15 \mathrm{~min}$, in 


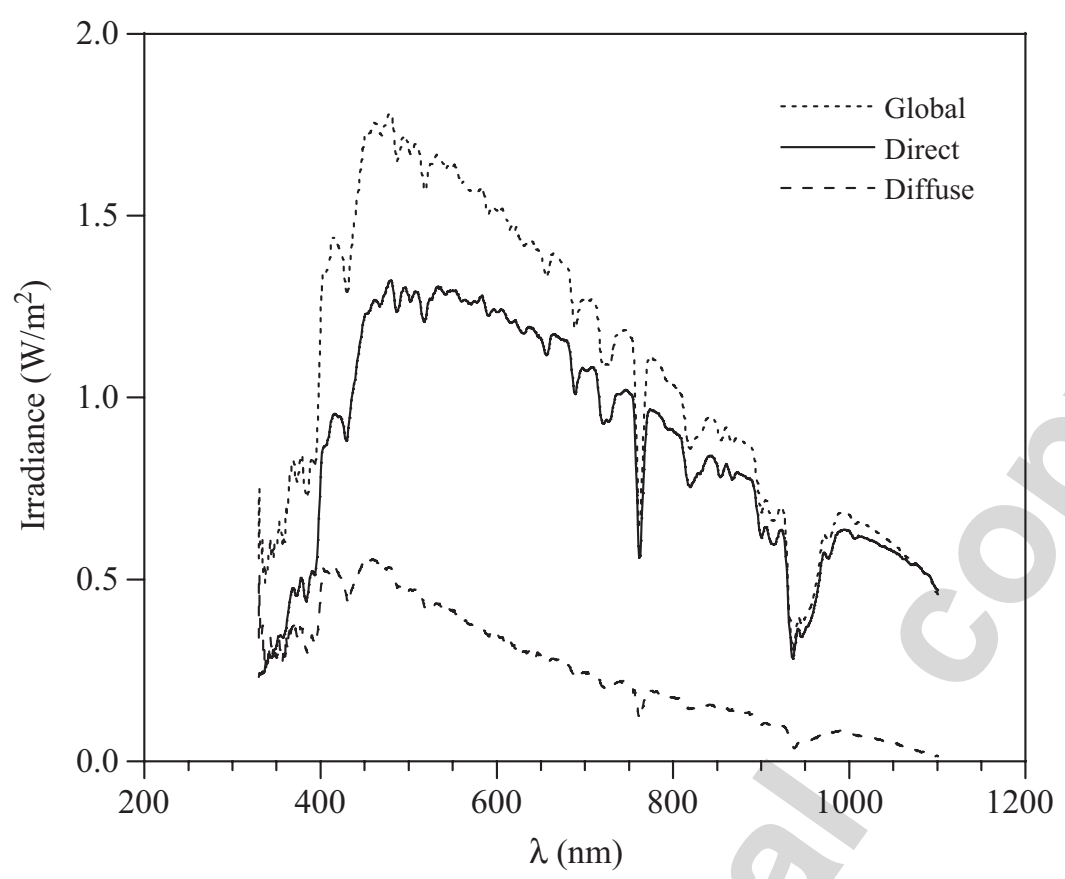

Fig. 5. Direct normal, global horizontal and diffuse horizontal spectral irradiance measured in Valencia on 26/05/2003, 1200 UTC.

winter from 0800 until 1600 UTC, and in summer from 0700 until 1700 UTC. Based on the daily spectral data files hourly files are created. In the header of these files appear the year/ month/day together with the UTC time, and the corresponding optical mass. Each file also stores a marker corresponding to the measurement location. The rest of the files are distributed in columns, the first corresponding to the wavelength (from 330 to $1100 \mathrm{~nm}$ ) then the direct normal spectral irradiance and the global irradiance on the horizontal plane. The fourth column stores the diffuse horizontal plane irradiance, a value calculated from the columns two and three. The fifth column contains the AOD, which is calculated using the method indicated in the following section. In Table 1 there is an example of a part of hourly file only from 330 to $340 \mathrm{~nm}$ wavelength.

The database files also contain a series of integrated solar radiation values and meteorological parameters that allow us to characterise the atmosphere in each measurement instant. These include the integrated direct normal irradiance (measured with an Eppley NIP pyrheliometer), the integrated global irradiance on a horizontal plane (measured with an Eppley 8-48 pyranometer) and the total and the UVB range integrated ultraviolet irradiance (measured with an Eppley TUV and a YES UVB-1, respectively), as well as the ambient temperature, atmospheric pressure and relative humidity. Fig. 6 shows the daily evolution of the integrated direct normal and global horizontal irradiances for $26 / 5 / 2003$. All these values have been measured by an automatic system belonging to the Valencia Solar Radiation Group and located on the terrace of the Industrial Engineering School building of the Polytechnic University of Valencia.

For data quality control it was decided to use clearness indices so that for each measurement day the following indices are determined:

$$
k_{t}=\frac{G}{G_{0}}
$$


Table 1

Example of a spectral hourly data section, only from 330 to $340 \mathrm{~nm}$

Place: Valencia

Year/month/day: 2003/5/26

Time: $11 \mathrm{~h}$ UTC Relative optical airmass : 1.07

\begin{tabular}{lllll}
\hline$\lambda(\mathrm{nm})$ & $G_{\lambda}\left(\mathrm{W} / \mathrm{m}^{2} \mathrm{~nm}\right)$ & $\mathrm{G}_{B \lambda}\left(\mathrm{W} / \mathrm{m}^{2} \mathrm{~nm}\right)$ & $G_{D \lambda}\left(\mathrm{W} / \mathrm{m}^{2} \mathrm{~nm}\right)$ & AOD \\
\hline 330 & 0.54184 & 0.217957 & 0.340025 & 0.537353 \\
331 & 0.72247 & 0.227623 & 0.511708 & 0.488168 \\
332 & 0.57458 & 0.225761 & 0.365544 & 0.528634 \\
333 & 0.55688 & 0.227936 & 0.345835 & 0.524972 \\
334 & 0.59082 & 0.231598 & 0.376375 & 0.491084 \\
335 & 0.51043 & 0.229378 & 0.298047 & 0.520589 \\
336 & 0.52590 & 0.232124 & 0.310977 & 0.514755 \\
337 & 0.47787 & 0.242332 & 0.253492 & 0.470889 \\
338 & 0.50979 & 0.245735 & 0.282264 & 0.480584 \\
339 & 0.50387 & 0.251968 & 0.270568 & 0.483248 \\
340 & 0.52124 & 0.258179 & 0.282183 & 0.472858 \\
\hline
\end{tabular}

$G_{\lambda}$ : global horizontal spectral irradiance; $G_{B \lambda}$ : direct normal spectral irradiance; $G_{D \lambda}$ : diffuse horizontal spectral irradiance; AOD: aerosol optical depth.

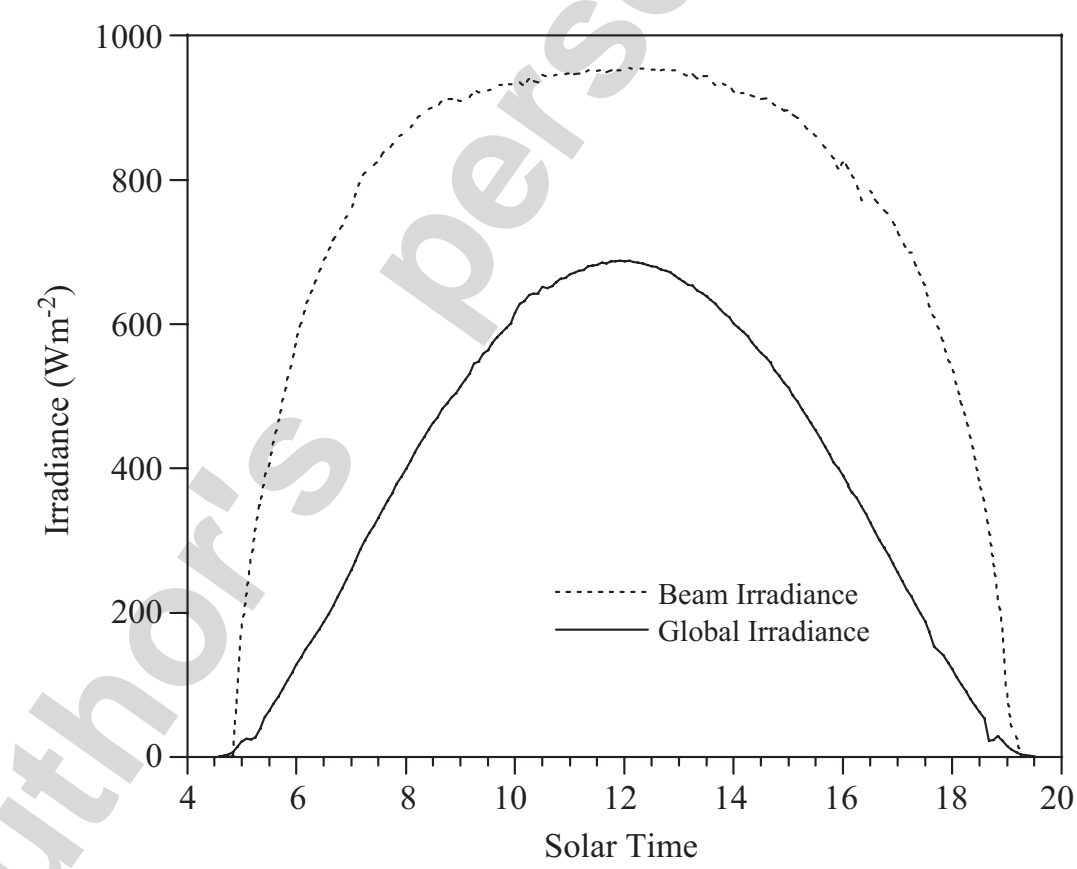

Fig. 6. Daily evolution of the integrated global horizontal and direct normal incidence irradiances. Valencia, $26 / 5 / 2003$.

$$
\begin{aligned}
& k_{N}=\frac{G_{N}}{G_{0 N}}, \\
& k_{N E}=\frac{G_{N E}}{G_{0 N}},
\end{aligned}
$$


where $G$ is the integrated global irradiance on a horizontal plane (measured by the pyranometer, $\left.\mathrm{W} / \mathrm{m}^{2}\right), G_{0}$ the extraterrestrial global irradiance on a horizontal plane $\left(\mathrm{W} / \mathrm{m}^{2}\right)$, $G_{N}$ the integrated direct normal irradiance (measured with the pyrheliometer, $\mathrm{W} / \mathrm{m}^{2}$ ), $G_{0 N}$ the integrated extraterrestrial direct normal irradiance $\left(\mathrm{W} / \mathrm{m}^{2}\right), G_{N E}$ the integrated direct normal irradiance (obtained by integrating the spectral measurements, $\mathrm{W} / \mathrm{m}^{2}$ ).

The extraterrestrial global irradiance on a horizontal plane have been calculated using:

$$
G_{0}=G_{\mathrm{sc}} E_{0} \cos \theta_{z}
$$

where $G_{s c}$ is the solar constant $\left(1367 \mathrm{~W} / \mathrm{m}^{2}\right), E_{0}$ the eccentricity correction factor of the earth's orbit, $\theta_{z}$ the zenith angle.

Furthermore a clearness index independent of the zenith angle, $k_{t}^{\prime}$ is also used. This is obtained by normalising the clarity index corresponding to an air mass equal to one. Perez et al. [32] define said index as

$$
k_{t}^{\prime}=k_{t} /[1.031 \exp (-1.4 /(0.9+9.4 / m)+0.1]
$$

where $m$ is the optical mass. A Linke turbidity factor of 1.4 was selected for this approximation. This may appear arbitrary, and a different value of the Linke turbidity factor would lead to a quite similar normalization function. Although with this expression the zenithal dependence is not completely removed, the results show noticeable gains in accuracy [32].

Analysing the above indices carefully it is possible to assess the quality of the experimental data.

\subsection{Aerosol optical depth}

From the spectral irradiance measurements at normal incidence, the total atmospheric optical depth is deduced employing the Bouguer-Lambert-Beer exponential law. In the case of a monochromatic radiation $\left(E_{n \lambda}\right)$ traversing the atmosphere, the Bouguer-Lambert-Beer law becomes:

$$
E_{n \lambda}=\left(1 / \rho^{2}\right) E_{0 \lambda} \exp \left(-\tau_{T \lambda} m\right)
$$

where $\rho$ is the mean relative Sun-Earth distance, $E_{0 \lambda}$ is the incident radiation at the top of the atmosphere, $m$ is the relative optical air mass and $\tau_{T \lambda}$ is the total atmospheric optical depth for all the different atmospheric extinction processes. From this spectral total atmospheric optical depth, the spectral AOD is determined by following a series of steps, which have been described by the authors in previous works [11,12].

In this case, to determine $\tau_{T \lambda}$ we employed the values of the extraterrestrial spectrum proposed by Gueymard [33,34] smoothing the data to the band pass of our spectroradiometer. For the air mass, the empirical expression proposed by Kasten and Young [35] is used. To calculate the AOD from the total atmospheric optical depth, the Rayleigh optical depth is calculated from the approximation of Bodhaine [36], and we assume the ozone absorption coefficients from Anderson and Mauersberger [37]. The total ozone amount was obtained daily from Total Ozone Mapping Spectrometer (TOMS) data [38], whilst for the $\mathrm{NO}_{2}$ the data corresponding to the Gueymard mid-latitudes model, given in Simple Model of Atmospheric Radiative Transfer of Sunshine (SMARTS ver. 2.9.2) [33], were used. As an example, Fig. 7 shows the AOD values for the 330-680 nm interval, 


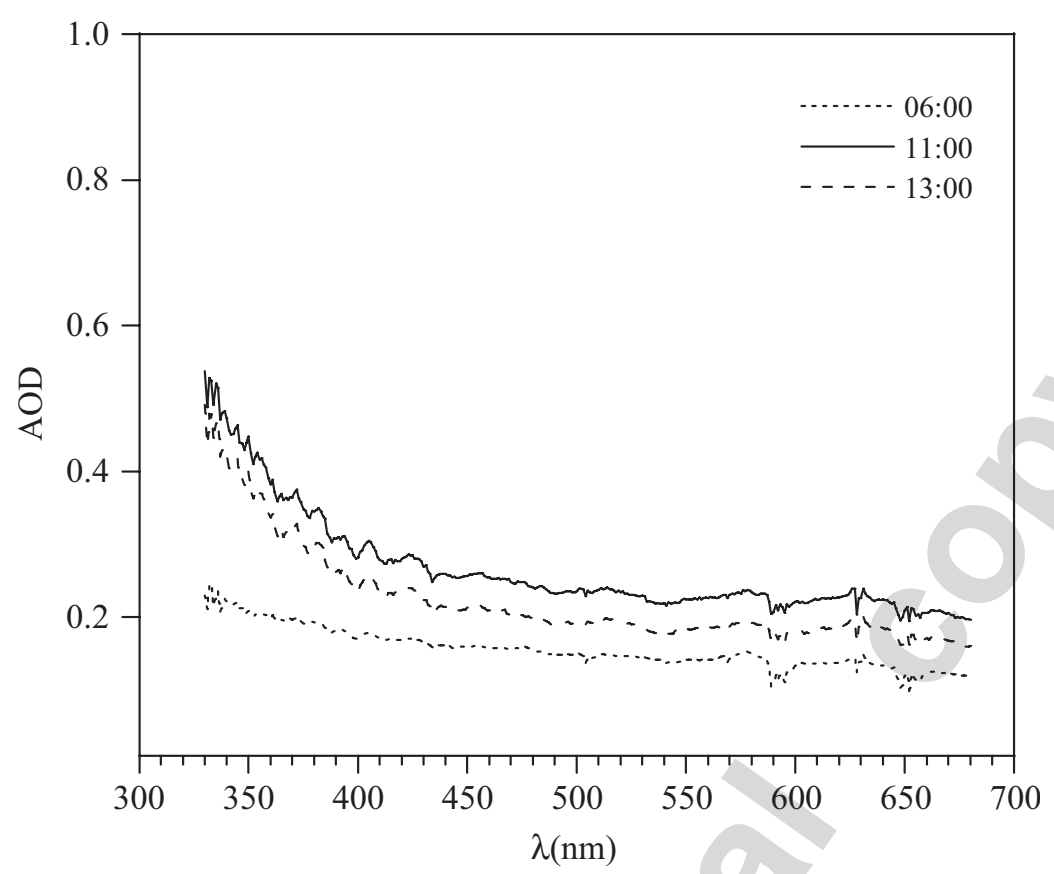

Fig. 7. Spectral AOD for the $330-680 \mathrm{~nm}$ range. Valencia, day $26 / 5 / 2003,0600,1100$ and 1300 UTC.

obtained by this methodology, corresponding to the times 0600,1100 and 1300 UTC on 26 May 2003 in Valencia.

Error propagation methods were applied to obtain the AOD error. Utrillas [39] developed a simplified method to estimate the error associated with the AOD values retrieved from spectral irradiance measurements. This method is similar to that developed by Russell et al. [40] and Schmid et al. [41]. In our case the error in the AOD is mainly conditioned by the error in the measurement of the direct spectral irradiance and the value of the optical air mass in the instant of the measurement. The authors have previously used this method with experimental measurements made at other sites [42] and the values that were obtained were similar to those presented by Kaufman et al. [43].

It has not been possible to compare the AOD values with the ones of the AERONET network because there is neither a station nearby Valencia nor with the same meteorological conditions. Nevertheless Estellés et al. [42] compared the Licor 1800 and Cimel 318 (instrument used in AERONET) results obtained in Veleta 2002 campaign. They concluded that the deviation in the retrieved AOD between both instruments in the visible range is $0.01-0.03$, depending on the channel.

The Angstrom parameters $(\alpha, \beta)$ have been calculated using a $\log -\log$ fitting of the experimental AOD values versus the wavelength, according to the Angstrom law:

$$
\operatorname{AOD}(\lambda)=\beta \lambda^{-\alpha} .
$$

Fig. 8 shows the $\alpha$-values obtained from the AOD values in Fig. 7.

From this analysis of the spectral AOD curves one can observe sometimes a discontinuity in the values around $560 \mathrm{~nm}$. Such phenomenon has been observed in other occasions, although more sporadically, by other authors $[12,44,45]$. The causes of this discontinuity could be:

(a) Change of the $558 \mathrm{~nm}$ filter in the Licor 1800. This fact should not produce a great difference in the nearby values because the instrument band pass is $6 \mathrm{~nm}$ and the step is 


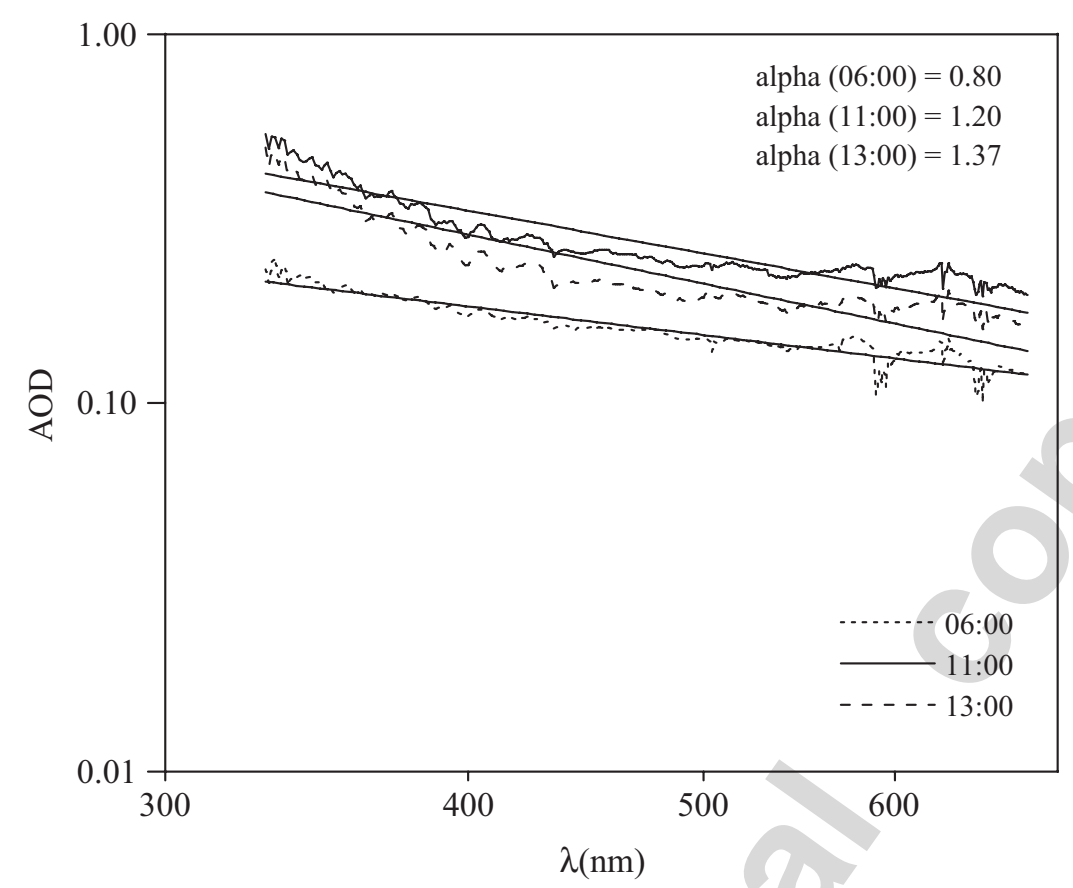

Fig. 8. Angstrom wavelength exponent for the $330-680 \mathrm{~nm}$ range. Valencia, day $26 / 5 / 2003,0600,1100$ and 1300 UTC.

$1 \mathrm{~nm}$. Furthermore, the discontinuity is not observed for all the measurement days and, when it is observed, it is for all the measurements.

(b) Physical reasons, such as the presence in the atmosphere of aerosols with different characteristics [12,14]. According to Moorthy et al. [44] the AOD and $\alpha$-values depend on the air mass origin when the spectral range analysed is below $750 \mathrm{~nm}$. Similar results have been obtained for studies in maritime environments [45].

The calculation of the Angstrom parameters for different spectral intervals (particularly the wavelength exponent $\alpha$ ) has been previously considered by other authors $[12,46]$. The choice of the intervals is mainly conditioned by the discontinuity that appears around $560 \mathrm{~nm}$ in the curve of AOD versus wavelength, which we believe could be related to the different modes observed in the size distributions. Concretely, when we consider shorter wavelengths, we obtain information about smaller particles, whereas when we consider longer wavelengths we obtain information related to greater particles.

\section{Conclusions}

An automatic system for the measurement of global and direct spectral solar irradiance in the 330-1100 nm range has been designed. The system uses two commercial LICOR1800 spectroradiometers equipped with a remote cosine receiver and a fibre optic.

For direct irradiance measurements a sun tracker has been designed and constructed which makes the system return to its rest position at the end of each measurement cycle. A computer program has also been designed to allow the control of the spectroradiometers and the tracker, which also implements a measurement protocol for generating a database of direct normal and global horizontal spectral irradiance. From these data, by using a 
subtractive method, the diffuse irradiance on a horizontal plane is calculated. Finally, using the Bouguer-Lambert-Beer law, the algorithm calculates total atmospheric thickness and aerosol optical depth in the 330-1100 nm interval.

\section{References}

[1] Riordan C. Joint EPRI-SERI spectral solar radiation data base project. Solar Cells 1987;21:337-42.

[2] Riordan C, Myers D, Rymes M, Hulstrom M, Marion W, Jenning C, et al. Spectral solar radiation data base at SERI. Sol Energy 1989;42:67-79.

[3] Nann S, Riordan C. Solar spectral irradiance under overcast skies. In: XXI IEEE photovoltaic specialist conference; 1990. p. 1110-5.

[4] Webb AR. Advances in solar ultraviolet spectroradiometry. European Commission. Air pollution research report 63, Luxembourg; 1997.

[5] Seckmeyer G, et al. The 1997 status of solar UV spectroradiometry in Germany: results from the national intercomparison of UV spectrradiometers. Garmish-Partenkirchen, Germany: Shaker-Verlag, AAchen; 1998.

[6] Holben BN, et al. AERONET-A federated instrument network and data archive for aerosol characterization. Remote Sensing Environ 1998;66:1-16.

[7] Holben BN, et al. An emerging ground-based aerosol climatology: aerosol optical depth from AERONET. J Geophys Res 2001;106:12067-97.

[8] Smirnov A, Holben BN, Kaufman YJ, Dubovik O, Eck TF, Slutsker I, et al. Optical properties of atmospheric aerosol in maritime environments. J Atmos Sci 2002;59:501-23.

[9] Cachorro VE, Utrillas P, Vergaz R, Durán P, de Frutos AM, Martinez-Lozano JA. A study about the atmospheric water vapor content determination in the $940 \mathrm{~nm}$ band using moderate spectral resolution measurements of direct solar irradiance. Appl Opt 1998;37:4678-89.

[10] Groebner J, Vergaz R, Cachorro VE, Henriquez D, Lamb K, Redondas A, et al. Intercomparison of aerosol optical depth measurements in the UVB using Brewer spectrophotometers and a Li-cor spectrophotometer. Geophys Res Lett 2001;28:1691-4.

[11] Martínez-Lozano JA, Utrillas MP, Tena F, Pedrós R, Cañada J, Boscá JV, et al. Aerosol optical characteristics from Summer Campaign in an Urban Coastal Mediterranean Area. IEEE Trans Geosci Remote Sensing 2001;39:1573-85.

[12] Pedrós R, Martinez-Lozano JA, Utrillas MP, Gómez-Amo JL, Tena F. Column-integrated aerosol optical properties from ground-based spectroradiometer measurements at Barrax (Spain) during the Digital Airborne Spectrometer Experiment (DAISEX) campaigns. J Geophys Res 2003;108:4571.

[13] Utrillas MP, Cañada J, Tamayo J, Martínez-Lozano JA. Column-integrated aerosol optical properties in the free troposphere. Case study: Sierra Nevada, Spain. IEEE Trans Geosci Remote Sensing 2004;42:2268-76.

[14] Osterwald CR, Emery KA. Spectroradiometric sun photometry. J Atmos Oceanic Technol 2000;17:1171-88.

[15] Carlund T, Landelius T, Josefsson W. Comparison and uncertainty of aerosol optical depth estimates derived from spectral and broadband measurements. J Appl Meteorol 2003;42:1598-610.

[16] Martínez-Lozano JA, Utrillas MP, Pedrós R, Tena F, Díaz JP, Expósito FJ, et al. Intercomparison of spectroradiometers for global and direct solar irradiance in the visible range. $\mathbf{J}$ Atmos Oceanic Technol 2003;20:997-1010.

[17] Michalsky J, Schlemmer J, Larson N, Harrison L, Berkheiser W, Laulainen N. Measurement of the seasonal and annual variability of total column aerosol in the northeastern US network. In: Proceedings of aerosols and atmospheric optics: radiative balance and visual air quality. Air and Water Management Association, Pittsburgh, Pennsylvania; 1994. p. 247-58.

[18] Davier PA. Sun-tracking mechanism using equatorial and ecliptic axes. Sol Energy 1993;50:487-9.

[19] Kalogirou SA. Design and construction of a one-axis sun-tracking system. Sol Energy 1996;57:465-9.

[20] Khalifa AN, Al-Mutawalli SS. Effect of two-axis sun tracking on the performance of compound parabolic concentrators. Energy Convers Manage 1998;39:1073-9.

[21] Roth P, Georgiev A, Boudinov H. Design and construction of a system for sun-tracking. Renew Energy 2003;29:393-402.

[22] Myers DR. Estimates of uncertainty for measured spectra in the SERI spectral solar radiation data base. Sol Energy 1989;43:347-53.

[23] Cannon TW. Spectral solar irradiance instrumentation and measurement techniques. Sol Cells 1986;18: 233-44. 
[24] Ferruz D. Diseño e implementación de un sistema seguidor solar para la medida de la irradiancia solar directa. Departamento de Informática. Universitat de Valencia 1999 (in Spanish).

[25] Blanco-Muriel M, Alarcón-Padilla D, López-Moratalla T, Lara-Coira M. Computing the solar vector. Sol Energy 2001;70:431-41.

[26] Nakajima T, Tanaka M, Yamakuchi T. Retrieval of the optical properties of aerosols from aureole extinction data. Appl Opt 1983;22:2951-9.

[27] Nakajima T, Tonna G, Rao R, Boi P, Kaufman Y, Holben B. Use of sky brightness measurements from remote sensing of particulate polydispersions. Appl Opt 1996;35:2675-86.

[28] Martínez-Lozano JA, Pedrós R, Flamant C, Utrillas MP, Tena F, Moreno J, et al. A multi-instrument approach for characterizing the atmospheric aerosol optical thickness during the STAAARTE/DAISEX-99 campaign. Geophys Res Lett 2002;29.

[29] Slaper H. Methods for intercomparing instruments. Advances in solar ultraviolet spectroradiometry, European Commission. Air pollution research report 63, Luxembourg; 1997. p. 155-64.

[30] Slaper H, Reinen AJ, Blumthaler M, Huber M, Kuik F. Comparing ground level spectrally resolved solar UV measurements using various instruments: a technique resolving effects of wavelength shift and slit width. Geophys Res Lett 1995;22:2721-4.

[31] Van Hoosier ME, Bantee JDF, Braeckner GE, Prinz DK. Absolute solar spectral irradiance 120-400 nm results from the SUSIM experiment on board Spacelab-2. Astrophys Lett Commun 1988;27:163-8.

[32] Perez R, Ineichen P, Seals R, Zelenka A. Making full use of the clearness index for parameterizing hourly insolation conditions. Sol Energy 1990;45:111-4.

[33] Gueymard C. Parameterized transmittance model for direct beam and circumsolar spectral irradiance. Sol Energy 2001;71:325-46.

[34] Gueymard C. The sun's total and spectral irradiance for solar energy applications and solar radiation models. Sol Energy 2004;76:423-53.

[35] Kasten F, Young MT. Revised optical air mass tables and approximation formula. Appl Opt 1989;28: $4735-8$.

[36] Bodhaine BA. Aerosol absorption measurements at Barrow, Mauna Loa and the south pole. J Geophys Res 1995; 100:8967-75.

[37] Anderson SM, Mauersberger K. Measurements of ozone absorption cross section in the Chappuis band. Geophys Res Lett 1992;19:933-6.

[38] TOMS, 2002. 〈http://toms.gsfc.nasa.gov/teacher/ozone_overhead.html >.

[39] Utrillas MP. Estudio de aerosoles a partir de medidas de irradiancia solar espectral. PhD thesis, Valencia University, Valencia, Spain; 1995 (in Spanish).

[40] Russell P, Livingston J, Dutton E, Pueschel R, Reagan J, DeFoor T, et al. Pinatubo and pre-Pinatubo optical depth spectra: Mauna Loa measurements, comparisons inferred particle size distributions, radiative effects, and relationships to LIDAR data. J Geophys Res 1993;98:22969-85.

[41] Schmid B, Mätzler C, Heimo A, Kämpfer N. Retrieval of optical depth and particle size distribution of tropospheric and stratospheric aerosols by means of sun photometry. IEEE Trans Geosci Remote Sensing 1997;35:172-82.

[42] Estellés V, Utrillas MP, Martínez-Lozano JA, Alcantara A, Alados-Arboledas L, Olmos FJ, et al. Intercomparison of spectroradiometers and sunphotometers for the determination of the aerosol optical depth during the VELETA2002 field campaign. J Geophys Res 2005;111:D17207.

[43] Kaufman YJ, Gitelson A, Karnieli A, Ganor E, Fraser RS, Nakajima T, et al. Size distribution and scattering phase function of aerosol particles retrieved from sky brightness measurements. J Geophys Res 1994;99:10341-56.

[44] Moorthy KK, Babu SS, Satheesh SK. Aerosol spectral optical depths over the Bay of Bengal: role of transport. Geophys Res Lett 2003;30:1249.

[45] Smirnov A, Holben BN, Dubovik O, Frouin R, Eck TF, Slutsker I. Maritime component in aerosol optical model derived from the aerosol robotic network data. J Geophys Res 2003;108.

[46] Vergaz R. Optical properties of atmospheric aerosols. Characterization of Cádiz gulf area. PhD thesis, Valladolid University, Valladolid, Spain, 2001 (in spanish). 